OPEN ACCESS

Edited by:

Svetlana Karakhanova, Universität Heidelberg, Germany

Reviewed by:

Junko Matsuzaki,

Roswell Park Cancer Institute,

United States

Amorette Barber,

Longwood University, United States

Per Thor Straten,

Herlev Hospital, Denmark

*Correspondence:

Sebastian Kobold

sebastian.kobold@

med.uni-muenchen.de

${ }^{\dagger}$ These authors have contributed equally to this work

Specialty section:

This article was submitted to Cancer Immunity and Immunotherapy, a section of the journal

Frontiers in Immunology

Received: 28 March 2018 Accepted: 08 August 2018

Published: 30 August 2018

Citation:

Rataj F, Kraus FBT, Chaloupka M, Grassmann S, Heise C, Cadilha BL,

Duewell P, Endres $S$ and Kobold $S$ (2018) PD1-CD28 Fusion Protein

Enables CD4+ T Cell Help for Adoptive T Cell Therapy in Models of Pancreatic Cancer and Non-hodgkin Lymphoma. Front. Immunol. 9:1955. doi: 10.3389/fimmu.2018.01955

\section{PD1-CD28 Fusion Protein Enables CD4+ T Cell Help for Adoptive T Cell Therapy in Models of Pancreatic Cancer and Non-hodgkin Lymphoma}

\author{
Felicitas Rataj ${ }^{1 \dagger}$, Fabian B. T. Kraus ${ }^{1 \dagger}$, Michael Chaloupka ${ }^{1}$, Simon Grassmann ${ }^{1}$, \\ Constanze Heise ${ }^{1}$, Bruno L. Cadilha ${ }^{1}$, Peter Duewell ${ }^{1}$, Stefan Endres ${ }^{1,2}$ and \\ Sebastian Kobold ${ }^{1,2 *}$
}

${ }^{1}$ Center of Integrated Protein Science Munich (CIPS-M) and Division of Clinical Pharmacology, Department of Medicine IV, Klinikum der Universität München, Member of the German Center for Lung Research (DZL), Munich, Germany, ${ }^{2}$ German Cancer Research Center (DKTK), Partner Site Munich, Heidelberg, Germany

Background: Interaction of the programmed death receptor 1 (PD-1) and its ligand, PD-L1, suppresses T cell activity and permits tumors to evade $T$ cell-mediated immune surveillance. We have recently demonstrated that antigen-specific CD8+ $T$ cells transduced with a PD1-CD28 fusion protein are protected from PD-1-mediated inhibition. We have now investigated the potential of PD1-CD28 fusion protein-transduced CD4+ T cells alone or in combination with CD8+ T cells for immunotherapy of pancreatic cancer and non-Hodgkin lymphoma.

Methods: OVA-specific CD4+ and CD8+ were retrovirally transduced with the PD1-CD28 fusion protein. Cytokine release, proliferation, cytotoxic activity, and phenotype of transduced T cells were assessed in the context of Panc02-OVA (murine pancreatic cancer model) and E.G7-PD-L1 (murine T cell lymphoma model) cells.

Results: Stimulation of PD1-CD28 fusion protein-transduced CD4+ T cells with anti-CD3 and recombinant PD-L1 induced specific $T$ cell activation, as measured by IFN-y release and T cell proliferation. Coculture with Panc02-OVA or E.G7-PD-L1 tumor cells also led to specific activation of CD4+ T cells. Cytokine release and $T$ cell proliferation was most effective when tumor cells simultaneously encountered genetically engineered CD4+ and CD8+ T cells. Synergy between both cell populations was also observed for specific tumor cell lysis. T cell cytotoxicity was mediated via granzyme B release and mediated enhanced tumor control in vivo. Transduced CD4+ and CD8+ T cells in co-culture with tumor cells developed a predominant central memory phenotype over time. Different ratios of CD4+ and CD8+ transduced $T$ cells led to a significant increase of IFN-y and IL-2 secretion positively correlating with CD4+ T cell numbers used. Mechanistically, IL-2 and $\mathrm{MHC}-\mathrm{I}$ were central to the synergistic activity of $\mathrm{CD} 4+$ and $\mathrm{CD} 8+\mathrm{T}$ cells, since neutralization of IL-2 prevented the crosstalk between these cell populations. 
Conclusion: PD1-CD28 fusion protein-transduced CD4+ T cells significantly improved anti-tumoral effect of fusion protein-transduced CD8+ T cells. Thus, our results indicate that PD1-CD28 fusion protein-transduced CD4+ T cells have the potential to overcome the PD-1-PD-L1 immunosuppressive axis in pancreatic cancer and non-Hodgkin lymphoma.

Keywords: adoptive T cell transfer, cancer immunotherapy, costimulation, PD-1-CD28 fusion protein, CD4+ T cells

\section{INTRODUCTION}

Cytotoxic T cells specifically recognize tumor antigens presented on major histocompatibility complex-1 (MHC-I). After binding to the tumor antigen in the context of MHC, T cells are activated, which results in the secretion of cytotoxic factors and target cell lysis $(1,2)$. This concept is utilized therapeutically for adoptive $\mathrm{T}$ cell therapy (ACT). Patient-derived, tumor-specific $\mathrm{T}$ cells are expanded ex vivo or, to further enhance tumor-specificity, are genetically modified. $T$ cell engineering usually follows two main approaches; either by introducing a $\mathrm{T}$ cell receptor specific for a given tumor-associated antigen or by equipping $\mathrm{T}$ cells with chimeric antigen receptors (CAR), which are synthetic receptors enabling tumor recognition. Following expansion, $\mathrm{T}$ cells are infused back to the patient in therapeutic intention (3). Pioneering work for ACT utilized tumor-infiltrating lymphocytes (TIL) for melanoma treatment yielding consistent durable response rates in subsets of patients. The challenges to generate these cells from tumor tissue of individual patients or even across entities has so far refrained this strategy from large scale clinical testing (4). Based on compelling preclinical and clinical data in hematological malignancies, ACT holds great promise for cancer immunotherapy. In 2017, the Food and Drug Administration (FDA) approved the first cellular therapy for refractory B-cell acute lymphoblastic leukemia (B-ALL) and diffuse large B cell lymphoma. Anti-CD19-CAR T cells are now part of the standard of care in the US, based on unparalleled remission rates and prolonged overall survival for patients with an otherwise very poor prognosis (5). In addition, ACT is under investigation for the treatment of other hematologic as well as more frequent nonhematological malignancies. Typically, ACT is performed with a mixture of $\mathrm{CD} 4+$ and $\mathrm{CD} 8+\mathrm{T}$ cells, which is dictated by the patient's own peripheral blood $\mathrm{T}$ cell ratio and the differential expansion status in cell culture. Some protocols also adjust for defined ratios, based on own evidence that this might be more beneficial (6-8). When being transduced for tumor specificity both cell types are being modified and in the case of CAR T cells, both cell populations are thought to be therapeutically relevant (9).

However, CD8 $+\mathrm{T}$ cells are generally considered more potent and more central for ACT efficacy. CD4+ T cells have a distinct functional and secretory phenotype from CD8+ $\mathrm{T}$ cells which is neither redundant nor overlapping. Importantly, CD4+ T cellderived cytokines play an important role in anti- but also in protumoral immunity $(10,11)$. While it is established that CD4+ $\mathrm{T}$ cells can be cytotoxic on their own, a major function lays in regulating trafficking, activation, proliferation, differentiation, and persistence of tumor-infiltrating cytotoxic CD8+ T cells (1215). Several studies have confirmed the helper function of tumorspecific CD4+ T cells and showed that the anti-tumor activity of combined treatment with $\mathrm{CD} 4+$ and $\mathrm{CD} 8+\mathrm{T}$ cells is more pronounced than that seen when using individual cell types. The exact mechanism of this synergy remains to be elucidated (16-18).

Despite the clinical success of ACT in defined indications, ACT is inherently limited by antigen-loss variants of tumor cells, side effects resulting from on- and off-target expression of the chosen antigen and low $\mathrm{T}$ cell infiltration into the tumor tissue. ACT failure is often associated with an increased expression of the programmed death-1 receptor (PD-1), a marker protein for T cell anergy, on previously activated T cells (19, 20). PD-1 signaling mediates $T$ cell suppression that prevents autoimmunity under physiological conditions and is therefore a key immune checkpoint on CD4+ and CD8+ T cells $(21,22)$. PD-L1, one of the two known ligands for PD-1, is broadly expressed on epithelial as well as hematological cells and shields these cells from $\mathrm{T}$ cell overactivation (23). Along these lines, tumors usurp this mechanism to evade anti-tumor immune responses (24). It is thereby not surprising, that undulating PD-L1 expression is found in most if not all human cancers at different levels and its expression is associated with dismal prognosis in the pre-immunotherapy era (25). Paradoxically, recognition of tumor cells by $\mathrm{T}$ cells transferred for ACT will result in $\mathrm{T}$ cell activation, upregulation of $\mathrm{PD}-1$ on the said $\mathrm{T}$ cell, but also of PD-L1 on the tumor cell. This will ultimately end in abrogation of $\mathrm{T}$ cell activity and thereby ACT failure (26). Clinical evidence that this state of anergy might be reverted when antagonizing the PD-1-PD-L1 axis has been shown in several phase III clinical trials testing anti-PD-1 or anti-PD-L1 antibodies in melanoma or non-small cell lung cancer (27-31). Based on these studies, it seems likely that a similar approach might also be of value for ACT. As both checkpoint blockade and ACT have severe side effects on their own, it might be advisable to develop more targeted strategies to overcome T cell anergy than systemically blocking important immune checkpoints.

To overcome PD-1 suppression selectively and to improve $\mathrm{ACT}$, we have developed a therapeutic concept that converts tumor-associated immunosuppression via the PD-1-PD-L1 axis into stimulation of tumor-specific $\mathrm{T}$ cells (32). We created a fusion receptor consisting of the extracellular domain of the PD1 receptor fused to the intracellular, $\mathrm{T}$ cell-activating domain of CD28. In the tumor tissue, PD-1-CD28 fusion proteinexpressing CD8 $+\mathrm{T}$ cells recognize tumor-derived PD-L1 and get locally activated. This results in tumor cell lysis and therapeutic 
benefit. It, however, remained unclear if the benefit is specific to $\mathrm{CD} 8+\mathrm{T}$ cells, and particularly if adding this fusion protein to $\mathrm{CD} 4+\mathrm{T}$ cells would further accelerate therapeutic activity. We hypothesized that our PD-1-CD28 fusion protein is not only functional in antigen-specific CD4 $+\mathrm{T}$ cells but also that simultaneous introduction in CD8 $+\mathrm{T}$ cells would further enhance $\mathrm{T}$ cell function. Here, we demonstrate that primary murine CD4+ $\mathrm{T}$ cells, expressing PD1-CD28 fusion protein, overcome $\mathrm{PD}$-L1-induced $\mathrm{T}$ cell anergy in murine models of pancreatic cancer and non-Hodgkin lymphoma. Coculture experiments demonstrate a synergism of gene-modified CD4+ and CD8+ T cells for anti-tumor activity, which was dependent on IL-2 secretion from CD4+ T cells. Our results indicate the potential of PD1-CD28 fusion protein-transduced CD4 $+\mathrm{T}$ cells to further improve ACT.

\section{MATERIALS AND METHODS Cell Lines}

Panc02-OVA, a murine pancreatic cancer cell line and E.G7OVA, a murine $\mathrm{T}$ cell lymphoma cell line, were previously described (32, 33). Panc02-OVA-PD-L1 and E.G7-OVA-PD-L1 were generated by transduction of Panc02-OVA or E.G7-OVA cells with pMXs-puro or pMXs (a generous gift from Toshio Kitamura, M.D., PhD, the Institute of Medical Science, University of Tokyo, Japan) encoding the full-length murine PD-L1 (SwissProt accession number Q9EP73). Panc02-OVA-PD-L1 cells were selected based on puromycin resistance. E.G7-OVA-PD-L1 cells were obtained by fluorescence activated cell sorting. Panc02-OVA and Panc02-OVA-PD-L1 were cultured in DMEM3+ (DMEM with $10 \%$ fetal bovine serum [FBS, Life Technologies, USA), 100 $\mathrm{U} / \mathrm{ml}$ penicillin and streptomycin (PS), and $2 \mathrm{mM}$ L-glutamine (all from PAA, Germany)]. E.G7-OVA-PD-L1 were cultured in RPMI 1,640 supplemented with 10\% FBS, $100 \mathrm{U} / \mathrm{ml}$ PS and $2 \mathrm{mM}$ L-glutamine, $1 \mathrm{mM}$ sodium pyruvate (PAA, Germany), and $1 \mathrm{mM}$ HEPES (Sigma Aldrich, Germany).The retroviral ecotrophic packaging cell line Platinum-E was purchased from Cell biolabs (USA). DMEM3 + medium for Platinum-E cells additionally contained $10 \mu \mathrm{g} / \mathrm{ml}$ puromycin and $1 \mu \mathrm{g} / \mathrm{ml}$ blasticidin (both from Sigma, Germany). Primary murine T cells were cultured in RPMI 1640 supplemented with 10\% FBS, 100 $\mathrm{U} / \mathrm{ml} \mathrm{PS}$ and $2 \mathrm{mM}$ L-glutamine, $1 \mathrm{mM}$ sodium pyruvate (PAA, Germany), $1 \mathrm{mM}$ HEPES (Sigma Aldrich, Germany), and $50 \mu \mathrm{M}$ $\beta$-mercaptoethanol.

\section{Mice}

Mice transgenic for a $\mathrm{T}$ cell receptor specific for ovalbumine (OT-1 or OT-2) were obtained from the Jackson laboratory (Bar Harbor, ME) (stock number 003831 for OT-1 and 004194 for OT2) and were bred in our animal facility under SPF conditions. Both mouse strains served as $\mathrm{T}$ cell donors for primary murine T cell transduction.

\section{Animal Experiments}

For in vivo studies wild type C57/Bl6 mice were purchased from Charles River. Tumors were induced by subcutaneous injection of $4 \times 10^{5}$ E-G7-OVA-PD-L1 tumor cells. Mice were randomized with regard to tumor size and treated via serial transfer of PTM-transduced or untransduced T cells: First, CD8+ T cells were injected i.v. $48 \mathrm{~h}$ later, CD4+ T cells were injected i.v. Tumor growth was assessed every other day in a blinded fashion and tumor volume was estimated according to the following formula: 4/3 $\times \pi \times L_{1}^{2} \times L_{2}$ (with $L_{1}$ defined as maximal diameter and $\mathrm{L}_{2}$ as the diameter perpendicular to $\mathrm{L}_{1}$ ). All experiments were approved by the local regulatory agency (Regierung von Oberbayern).

\section{T Cell Transduction}

The PD1-CD28 fusion protein was described previously (32). The retroviral vector pMP71 (kindly provided by Christopher Baum, M.D., Institute of Experimental Hematology, Medizinische Hochschule Hannover, Germany) was utilized for all transduction experiments. Detailed protocols for murine $\mathrm{T}$ cell transduction have been published (34-37). In brief, pMP71 PD1-CD28 vector was transfected into Platinum-E cells and retrovirus-containing supernatants were collected for transduction of murine $\mathrm{T}$ cells. Primary murine $\mathrm{T}$ cells were first stimulated with anti-CD3e and anti-CD28 antibody (eBioscience, clones 145-2C11 and 37.51, respectively) and recombinant IL-2 (Novartis, Switzerland). Priot to transduction, anti-CD3- and anti-CD28 beads (Life technologies, USA) were added. Recombinant IL-15 (Peprotech, Germany) was used for $\mathrm{T}$ cell expansion. The CD4 $+\mathrm{T}$ cell fraction was purified on the day of spleen extraction by magnetic activated cell sorting using a CD4+ T cell isolation kit (Miltenyi Biotec, Germany).

\section{Flow Cytometry}

For multi-color flow cytometry, a BD FACS Canto II (BD bioscience, Germany) together with the following antibody panels was used. For purity testing and analysis of transduction efficiencies, anti-PD-1 (APC, clone RMP-30, BioLegend, USA), anti-CD8 (Pacific Blue ${ }^{\mathrm{TM}}$, clone 53-6.7, BioLegend, USA) and anti-CD4 (Pacific Blue ${ }^{\mathrm{TM}}$ e, clone GK1.5, BioLegend, USA) were used. For analysis of MHC I-, MHCII-, and PD-L1expression, tumor cells were stained with anti-MHCI (PE, clone M1/42.3.9.8, Elabscience, USA), anti-MHCII (APC, clone M5/114.15.2, eBioscience, USA) and anti-CD274 (PE/Cy7, clone 10F.9G2, BioLegend, USA). Rat IgG2a- (PE, clone \#54447, R\&D Systems, USA), Rat IgG2b kappa-(APC, clone eB149/10H5, eBioscience, USA) and Rat IgG2b kappa-antibodies (PE/Cy7, clone RTK4530, BioLegend, USA) were applied as isotype control. For proliferation analysis in antibody-stimulation assays, $\mathrm{T}$ cells were stained with anti-PD-1 (APC, clone RMP-30, BioLegend, USA), anti-CD28 (APC, clone 37.51, BioLegend, USA), anti-CD4 (Pacific Blue ${ }^{\mathrm{TM}}$, clone GK1.5, BioLegend, USA), and Zombie aqua fixable viability dye (BioLegend, USA) prior to fixation and permeabilization with FoxP3/Transcription Factor Staining Buffer Set (eBioscience, USA). For staining of intracellular proteins, anti-Ki67 (PE, clone 16A8, BioLegend, USA) and anti-EOMES (PE/Cy7, clone DAN11mag, eBioscience, USA) were added. Cells were washed and resuspended in PBS (Lonza, Switzerland) containing count bright absolute counting beads (Life technologies, USA). For proliferation analysis in cocultures of $\mathrm{T}$ cells and tumor cells, $\mathrm{T}$ cells were stained 
with anti-PD-1 (APC, clone RMP-30, BioLegend, USA), antiCD4 (Pacific Blue ${ }^{\mathrm{TM}}$, clone GK1.5, BioLegend, USA), antiCD8 (APC/Cy7, clone 53-6.7, BioLegend, USA), and Zombie aqua fixable viability dye (BioLegend, USA). Equal amounts of counting beads (Life technologies, USA) were added to each sample. The antibody panel for $\mathrm{T}$ cell phenotyping consisted of anti-PD-1 (FITC, clone 29F.1a12, BioLegend, USA), anti-CD8 (APC/Cy7, clone 53-6.7, BioLegend, USA), anti-CD4 (PE/Cy7, clone RM4-5, BioLegend, USA), anti-CD62L (Pacific Blue ${ }^{\mathrm{TM}}$, clone MEL-14, BioLegend, USA), anti-CCR7 (PerCP/Cy5.5, clone 4B12, BioLegend, USA), and Zombie aqua fixable viability dye (BioLegend, USA).

\section{MHC I-, MHC II-, and PD-L1-Profiling of Tumor Cells}

For the analysis of MHC I-, MHC II-, and PD-L1-expression on Panc02-OVA and E.G7-OVA-PD-L1, $5 \times 10^{4}$ tumor cells were stimulated for $48 \mathrm{~h}$ with recombinant murine IFN- $\gamma$ (Peprotech, USA) at increasing concentrations of 2, 20, or $100 \mathrm{ng} / \mathrm{ml}$ respectively and analyzed by flow cytometry as described above.

\section{Antibody-Stimulation Assays}

For antibody-stimulation assays, $\mathrm{T}$ cells were stimulated with anti-CD3 antibody (100 ng/ml, clone 145-2C11, eBioscience), anti-CD3 antibody and recombinant PD-L1-Fc chimera protein $(5 \mu \mathrm{g} / \mathrm{ml}, \mathrm{R} \& \mathrm{D}$ Systems) or anti-CD3 antibody and anti-CD28 antibody $(2 \mu \mathrm{g} / \mathrm{ml}$, clone 37.51 , eBioscience) for $48 \mathrm{~h}$. Mitotic activity and CD28 surface expression was analyzed by flow cytometry. Cells were stained as indicated and cell numbers were normalized with counting beads (Life Technologies, Germany). Cytokine release was quantified by ELISA (IL-2 and IFN- $\gamma$, both $\mathrm{BD})$.

\section{Cocultures of T Cells and Tumor Cells}

For $\mathrm{T}$ cell-tumor cell cocultures, CD8+ and CD4+ $\mathrm{T}$ cells (in a $3: 1,1: 1$, or $1: 3$ cell ratio) were prestimulated with antiCD3 antibody (100 ng/ml, clone 145-2C11, eBioscience) and recombinant PD-L1-Fc chimera protein $(5 \mu \mathrm{g} / \mathrm{ml}$, R\&D Systems) for $24 \mathrm{~h}$, as described above. $\mathrm{T}$ cells were then cocultured for $16 \mathrm{~h}$ with either E.G7-OVA-PD-L1, Panc02-OVA, or PancOVA-PD-L1 tumor cells in a 10:1 effector to target cell ratio. Cytokine release was quantified by ELISA (IL-2 and IFN$\gamma)$. For cytotoxicity assays, tumor cell-derived LDH release was quantified after $16 \mathrm{~h}$ using CytoTox $96^{\circledR}$ Non-Radioactive Cytotoxicity Assay (Promega, USA). Granzyme B secretion was determined using Mouse Granzyme B DuoSet ${ }^{\circledR}$ ELISA (R\&D systems, USA). For T cell phenotyping and proliferation assays, $\mathrm{T}$ cells were cocultured with Panc-OVA-PD-L1 for $36 \mathrm{~h}$, as described above. T cell phenotype and proliferation was analyzed by flow cytometry as described above.

\section{MHC I, MHC II, and IL-2 Neutralization Assays}

For MHC I, MHC II, and IL-2 neutralization experiments, CD8+ and $\mathrm{CD} 4+\mathrm{T}$ cells (in a 1:1 ratio) were prestimulated with antiCD3 antibody and recombinant PD-L1-Fc chimera for $24 \mathrm{~h}$. Subsequently, T cells and Panc02-OVA cells were cocultured at a
10:1 effector to target cell ratio. Anti-mouse MHC class I antibody $(10 \mu \mathrm{g} / \mathrm{ml}$, clone $\mathrm{M} 1 / 42.3 .9 .8$, InVivoMAb), anti-mouse MHC class II antibody $(10 \mu \mathrm{g} / \mathrm{ml}$, clone M5/114.15.2, eBioscience) and LEAF purified anti-mouse IL-2 antibody $(10 \mu \mathrm{g} / \mathrm{ml}$, clone JES6-1A12, BioLegend) were added during prestimulation and co-culture. Supernatants were analyzed for IFN- $\gamma$ by ELISA.

\section{Statistical Analysis}

For statistical analysis, GraphPad Prism software version 7.04 was used. Reported values are continuous. Differences between experimental conditions were analyzed using the unpaired twosided Student's $t$-test. $P$-values $<0.05$ were considered as significant. Data shown are mean values \pm SEM of at least three biological replicates representative for three independent experiments as indicated.

\section{RESULTS}

\section{Functional Analysis of PD1-CD28 Fusion Protein (PTM) in CD4+ T Cells}

To characterize the functionality of PTM in CD4+ T cells, we transduced PTM into primary murine CD4+ T cells. PTMtransduced and untransduced $\mathrm{T}$ cells were then stimulated with anti-CD3 antibody, anti-CD3 antibody and recombinant PDL1 or anti-CD3 antibody and anti-CD28 antibody for $48 \mathrm{~h}$. CD4+ PTM-transduced T cells showed significantly higher IFN$\gamma$ release as compared to untransduced $\mathrm{T}$ cells (Figure 1A). $\mathrm{T}$ cell activation was paralleled by an increase in $\mathrm{T}$ cell viability and $\mathrm{T}$ cell proliferation (Figures 1B,C). Untransduced CD4+ T cells were more strongly stimulated by anti-CD3 than PTM-transduced CD4+ T cells, while combination with antiCD28 antibodies brought PTM-transduced T cells to a similar level of stimulation as untransduced $\mathrm{T}$ cells in this control condition. Similarly, expression of the mitogenic marker Ki67 was higher in PTM-transduced T cells than in untransduced T cells (Figure 1D). Expression of Eomesodermin (EOMES), a $\mathrm{T}$ cell differentiation marker, was highest for anti-CD3 and PD-L1stimulated, transduced $\mathrm{T}$ cells compared to untransduced cells (Figure 1E). Together, these results demonstrate that PTM is functional in CD4+ T cells and enhances their functionality.

\section{Functional Analysis of PTM-Transduced T Cells Cocultured With Tumor Cells}

To assess the therapeutic potential of PTM-transduced CD4+ $\mathrm{T}$ cells in vitro, we prestimulated antigen-specific CD4+ or CD8+ PTM-transduced or untransduced $\mathrm{T}$ cells at a ratio of 1:1 with anti-CD3 antibody and recombinant PD-L1 for $24 \mathrm{~h}$. Prestimulation was performed to mimic primary antigen contact and to induce partial anergy of the cells, as expected in the tumor environment. CD4+ or CD8+, untransduced, or transduced $\mathrm{T}$ cells were then cocultured alone or in different combinations with either Panc02-OVA cells or E.G7-PD-L1 cells. PTM-transduced CD4 + and CD8 + T cells produced more IFN- $\gamma$ in contact with either cell line compared to untransduced $\mathrm{T}$ cells (Figure 2A). Highest IFN- $\gamma$ secretion was measured for both tumor cell lines when PTM-transduced CD4+ and PTMtransduced CD8+ were combined. The same effect was observed 


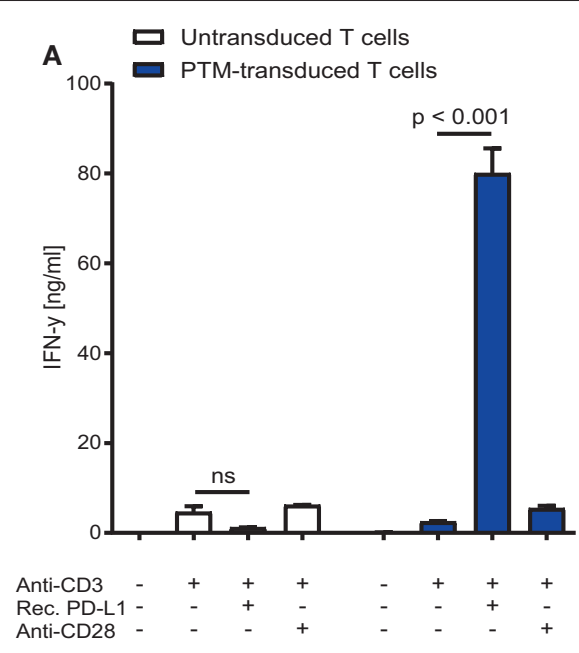

B Untransduced T cells
$\square$ PTM-transduced T cells

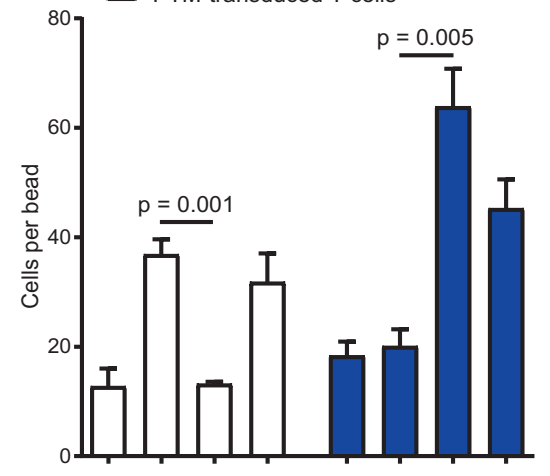

Anti-CD3

Rec. PD-L1

Anti-CD28
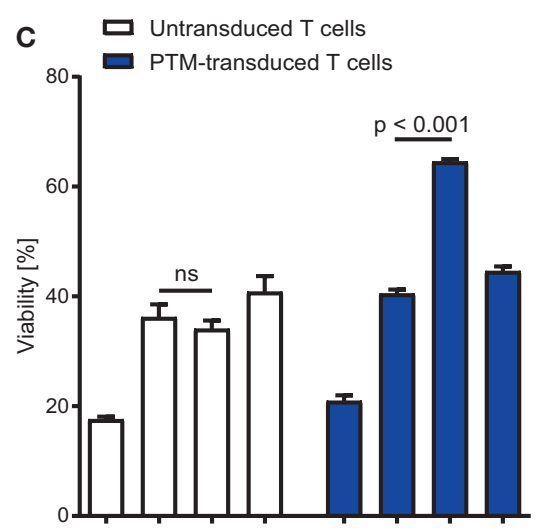

Anti-CD3

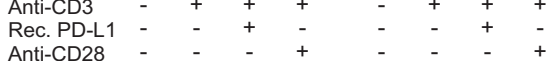

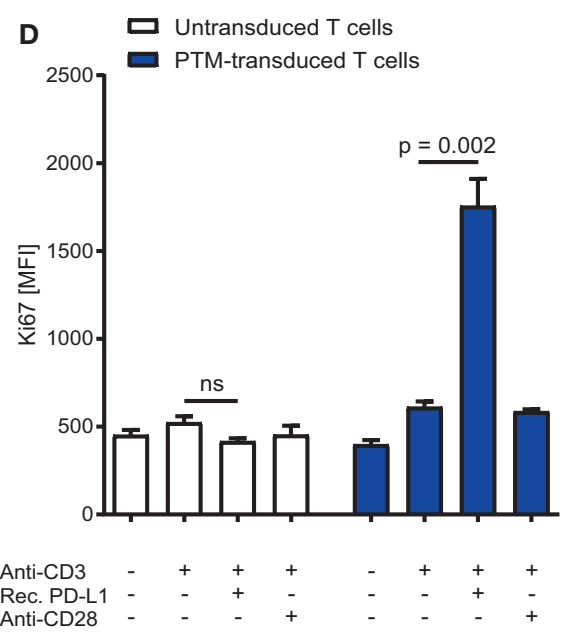

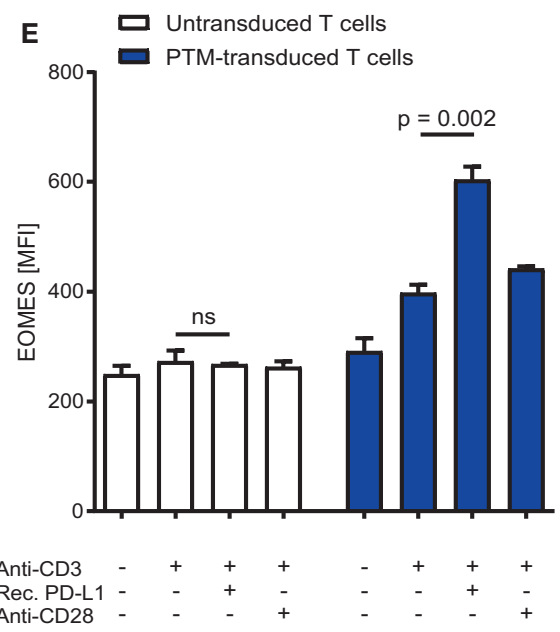

FIGURE 1 | In vitro characterization of PD1-CD28 fusion protein (PTM)-transduced CD4+ T cells. PTM-transduced or untransduced primary murine CD4+ T cells were either stimulated with anti-CD3 antibody, anti-CD3 antibody, and recombinant PD-L1 or anti-CD3 antibody and anti-CD28 antibody. (A) Interferon- $\gamma$ (IFN- $\gamma$ ) secretion was measured by enzyme linked immunosorbent assay (ELISA). (B) T cell number was analyzed by flow cytometry and normalized to standardized counting beads. (C) Viability of T cells was assessed by flow cytometry. (D) After $48 \mathrm{~h}$ of stimulation T cells were intracellularly stained for Ki67, a mitosis marker or (E) for the differentiation marker eomesodermin (EOMES). Experiments (A-E) are representative of three independent experiments each performed in triplicates. Bars represent SEM and $P$ values from Student's $t$-test are shown. All tests are two-sided. 
for IL-2 release (Figure 2B). T cell activation was followed by a similar effect on $\mathrm{T}$ cell-mediated cytotoxicity. CD4+ and CD8+ PTM-transduced T cells, prestimulated individually, induced significant lysis of Panc02-OVA and E.G7-PD-L1 cells as compared to untransduced $\mathrm{T}$ cells (Figure 2C). Similar to cytokine production, cytotoxic activity was highest, when CD4+ and CD8+ PTM-transduced T cells were cocultured with tumor cells as compared to control conditions. Mechanistically, T cell cytotoxicity correlated with granzyme B release indicating that $\mathrm{T}$ cell degranulation is the mode of action, which is boosted by PTM transduction (Figure 2D). T cell cytotoxicity was accompanied by an increase in the number of CD8+ T cells in coculture with CD4+ $\mathrm{T}$ cells and Panc02-OVA (Figure 2E). PTM-transduced CD4+ $\mathrm{T}$ cells in coculture with Panc02OVA-PD-L1 cells developed a predominant central memory phenotype, defined by CCR7+ and CD62L + expression, over time (Supplementary Figure 1A). The effect on CD4+ T cells was strongest in the presence of untransduced or PTMtransduced CD8+ T cells. However, PTM-expression on CD8+ $\mathrm{T}$ cells alone, did not have an influence on the CD4+ $\mathrm{T}$ cell phenotype. CD8 $+\mathrm{T}$ cells, in contrast, differentiated into central memory $\mathrm{T}$ cells within the same experimental setting (Supplementary Figure 1B). In these cocultures, the amount of effector memory T cells was reduced in both, CD4+ and CD8+ T cells transduced with PTM (Supplementary Figures 1C,D). Our results suggest that CD4+ PTM-transduced T cells have therapeutic activity in vitro and point toward a synergistic collaboration of CD4+ and CD8+ T cells. Of note, this effect was highest when PTM was expressed by both T cell subsets. In vivo, combined treatment of OT1-PTM with OT2-PTM T cells mediated enhanced tumor control over PTM-transduced OT1 T cells, OT1 plus OT2 T cells and OT1 plus PTM-OT2 T cells in the EG7-PD-L1 model (Figure 2F). These results indicate the potential value of the strategy in vivo.

\section{CD4+ to CD8+ T Cell Ratio Positively Influence the Activity of PTM-Transduced T Cells via IL-2 in Coculture With Tumor Cells}

To test the $\mathrm{CD} 4+$ to $\mathrm{CD} 8+\mathrm{T}$ cell ratio with the highest synergistic potential, we prestimulated antigen-specific, untransduced, or PTM-transduced CD8 + T cells and increasing numbers of antigen-specific, untransduced, or PTM-transduced CD4+ T cells with anti-CD3 antibody plus recombinant PD-L1. CD4+- or CD8+-, untransduced or transduced $\mathrm{T}$ cells were then cocultured alone or in different combinations with either Panc02-OVA or E.G7-PD-L1. In both tumor models, IFN- $\gamma$ secretion, as indicator for $\mathrm{T}$ cell activation, was highest when $\mathrm{PTM}+\mathrm{CD} 4+$ and PTM+ CD8+ T cells were combined (Figures 3A,B). IFN- $\gamma$ level positively correlated with the number of CD4+ $\mathrm{T}$ cells present in the coculture, accompanied by comparable IL-2 levels (Figures 3C,D). IL-2 levels were highest when PTM+ CD4+ and PTM+ CD8+ were cocultured with target cells. IL-2 production was tightly correlated with the number of CD4+ cells, pointing toward a potential role of IL-2 in their collaborative activity. To test this hypothesis, $\mathrm{T}$ cells were prestimulated and incubated with Panc02-OVA cells in the presence of anti-IL-2 neutralizing antibody. T cell activation, measured by IFN-y release, was almost abrogated through neutralization of IL-2 (Figure 3E). Similarly, synergy in $\mathrm{T}$ cell cytotoxicity was also blocked by anti-IL-2 neutralizing antibody in cocultures of Panc02-OVA cells with PTM+ CD4+ and PTM + CD8 $+\mathrm{T}$ cells (Supplementary Figure 2). Taken together, our results demonstrate that the synergistic effect of transduced CD4+ and CD8 + T cells is dose-dependent and is mediated by IL- 2 .

\section{Synergistic Activity Is Dependent on PD-L1 and MHC I but Not on MHC II Expression}

To further delineate the synergistic action of OT1-PTM and OT2-PTM T cells, we addressed the expression of potential components of the system on the tumor cell side. We therefore analyzed MHC I for OT1 T cell recognition, PD-L1 for PTM$\mathrm{T}$ cell activation and MHC II for OT2 $\mathrm{T}$ cell activation. In both models-Panc02-OVA and EG7-PD-L1-we found strong expression of MHC I but not of MHC II (Figures 4A,B). Not surprisingly, PD-L1 was constitutively overexpressed on EG7PD-L1 and could be induced on Panc02-OVA upon IFN- $\gamma$ stimulation (Figures 4A,B). Functionally, the observed synergy on EG7-PD-L1 of OT1-PTM and OT2-PTM T cells (Figure 4C) was entirely abrogated on OVA negative EL4 T cells (Figure 4D). Importantly this was not due to lack of MHC I or PD-L1 expression (not shown). Identical results were found when EG7PD-L1 were pretreated with MHC I-blocking antibodies. As in the absence of OVA, T cell activity was entirely abrogated (Figure 4E). In contrast, MHC II-blockade did not impact on T cell recognition by combined OT1-PTM and OT2-PTM T cells (Figure 4F). These results indicate that both PD-L1 and MHC I but not MHC II are essential for the activity of our proposed strategy.

\section{DISCUSSION}

ACT, especially for solid tumors, is often limited by the immunosuppressive tumor milieu. Tumor cells evade an efficient tumor immune response especially via the PD-1-PD-L1 axis. Here, we report that CD4+ $\mathrm{T}$ cells, expressing a PD1-CD28 fusion receptor, have the potential to overcome PD-L1-mediated $\mathrm{T}$ cell suppression. We hypothesized that PTM-transduced $\mathrm{CD} 4+\mathrm{T}$ cells might further boost the efficacy of $\mathrm{CD} 8+\mathrm{T}$ cells in vitro, pointing toward potential avenues for translation of the approach.

Inhibitory receptors, such as PD-1 and CTLA-4, are important checkpoint molecules that prevent autoimmunity under physiological conditions. However, when expressed by tumor-infiltrating $\mathrm{T}$ cells these molecules strongly prevent an effective anti-tumor response. Following a similar strategy, a costimulatory CTLA-4-CD28 fusion receptor was shown to induce large amounts of IL-2 and high proliferation of CD4+ $\mathrm{T}$ cells when introduced in the latter, strengthening the idea of such fusion proteins to support CD4+ $\mathrm{T}$ cell activity (38). We previously described a PD1-CD28 fusion protein 
A

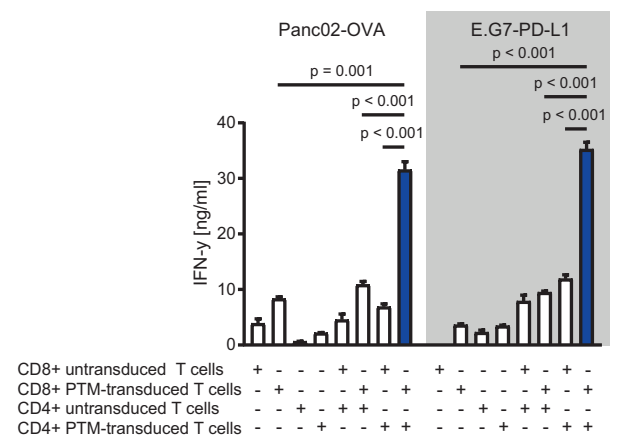

C

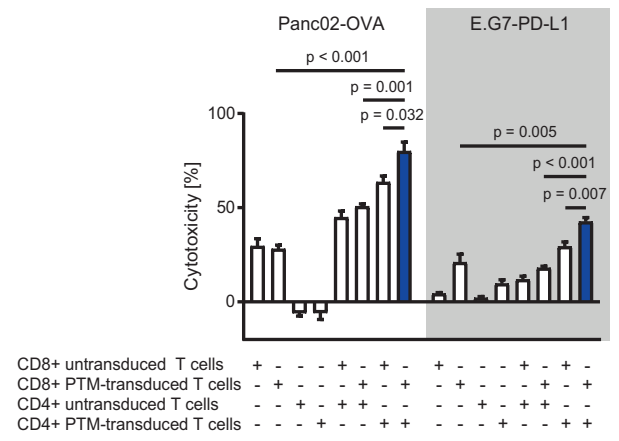

B

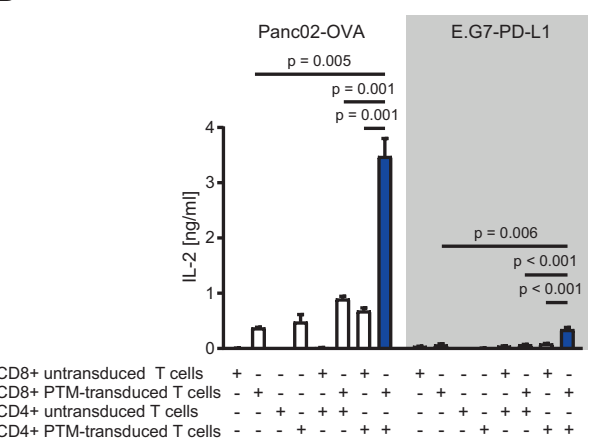

D
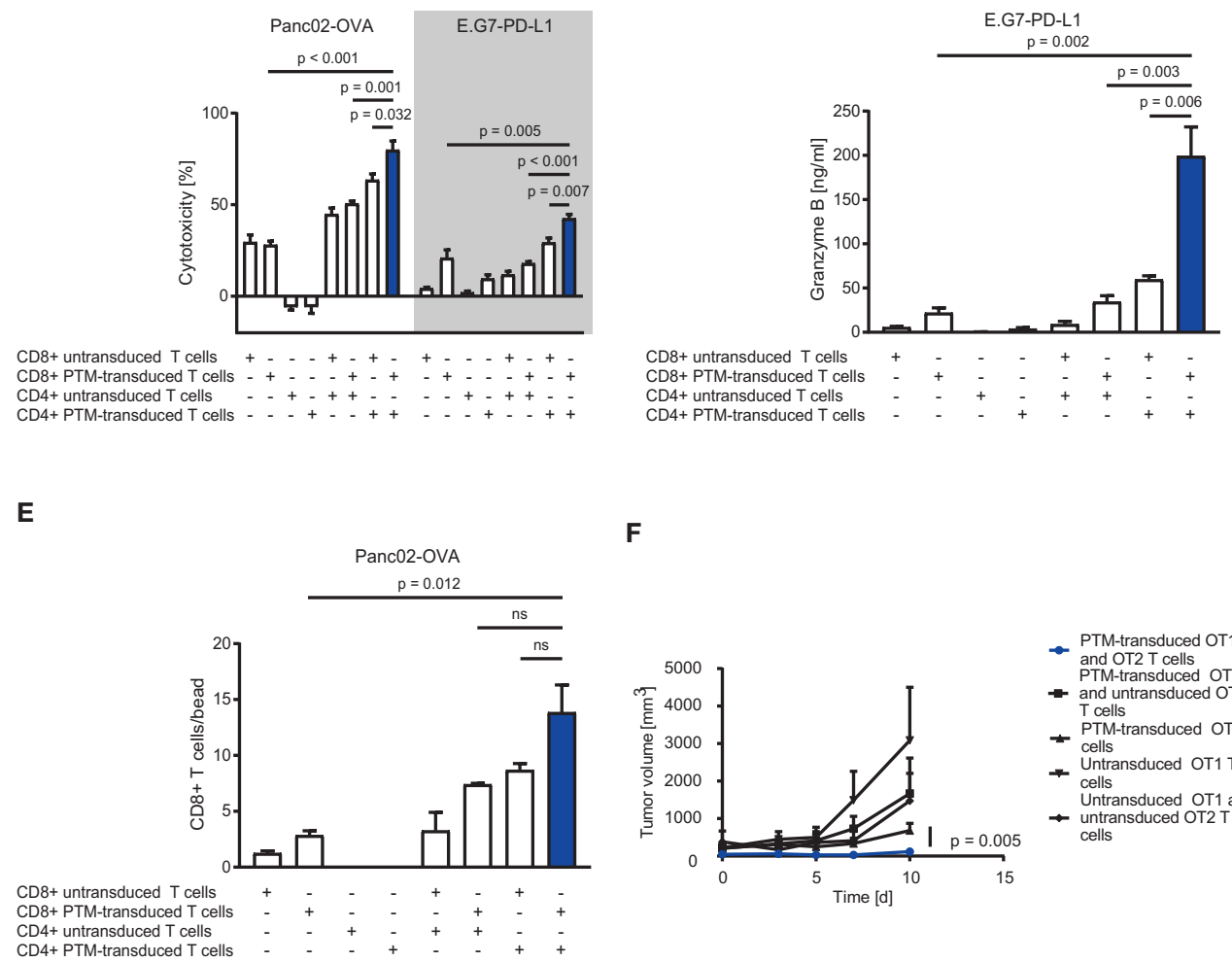

$\mathbf{F}$

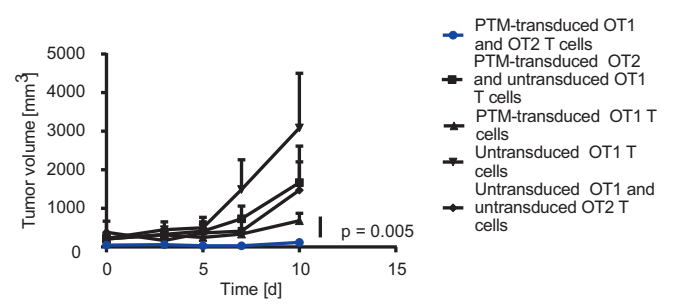

FIGURE 2 | In vitro and in vivo assessment of anti-tumor efficacy of PD1-CD28 fusion receptor (PTM receptor)-transduced CD4+ and CD8+ T cells. (A) PTM-transduced, untransduced primary murine OT-1, PTM-transduced, untransduced primary murine OT-2T cells, or OT-1 together with OT-2T cells were prestimulated for $24 \mathrm{~h}$ with anti-CD3 antibody plus recombinant PD-L1. T cells were then cocultured with Panc02-OVA or E.G7-PD-L1 cells. Interferon- $\gamma$ (IFN- $\gamma)$ secretion was measured by enzyme linked immunosorbent assay (ELISA). (B) Interleukin-2 (IL-2) release was measured by ELISA. (C) PTM-transduced, untransduced primary murine OT-1, PTM-transduced, untransduced primary murine OT-2T cells, or OT-1 together with OT-2T cells were prestimulated for $24 \mathrm{~h}$ with anti-CD3 antibody and recombinant PD-L1. In the meantime, Panc02-OVA or E.G7-PD-L1 cells were seeded and grown prior to the addition of T cells. LDH release measurement from lysed tumor cells was performed after $16 \mathrm{~h}$ of coculture. (D) Granzyme B secretion by T cells cocultured with E.G7-PD-L1 cells for 16 h measured by ELISA. (E) PTM-transduced, untransduced primary murine OT-1, PTM-transduced, untransduced primary murine OT-2T cells or OT-1 together with OT-2T cells were prestimulated for $24 \mathrm{~h}$ with anti-CD3 antibody plus recombinant PD-L1 and then cocultured with Panc02-OVA cells. T cell numbers were analyzed by flow cytometry and normalized to standardized counting beads. (F) 30 mice were subcutaneously injected with E.G7-OVA-PD-L1 tumor cells in two independent experiments. As soon as all tumors were established, the mice were randomized, assigned to five different treatment groups and treated with either PTM-transduced $(n=6)$ or untransduced primary murine OT1 T cells $(n=7)$ or with PTM-transduced $(n=4)$ or untransduced $(n=4)$ primary OT2 T cells in combination with OT1 T cells or PTM-transduced OT-1 T cells $(n=9)$. Tumor growth was assessed every other day in a blinded fashion and tumor volume was calculated as indicated. Pooled data from two independent experiments is shown here. Curves are censored by the time the first mice had to be taken out of the experiment either due to tumor size or ulceration (day 10). Experiments (A-E) are representative of three independent experiments each performed in triplicates. Experiment (F) represents pooled data of two independent experiments. Bars represent SEM and $P$ values from Student's $t$-test are shown. All tests are two-sided. 


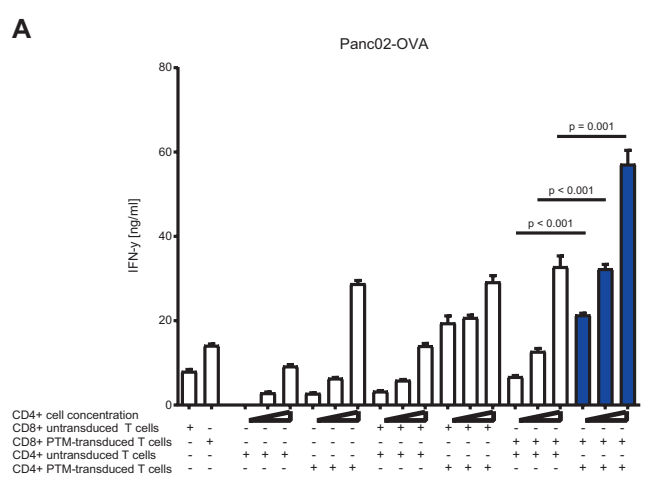

C

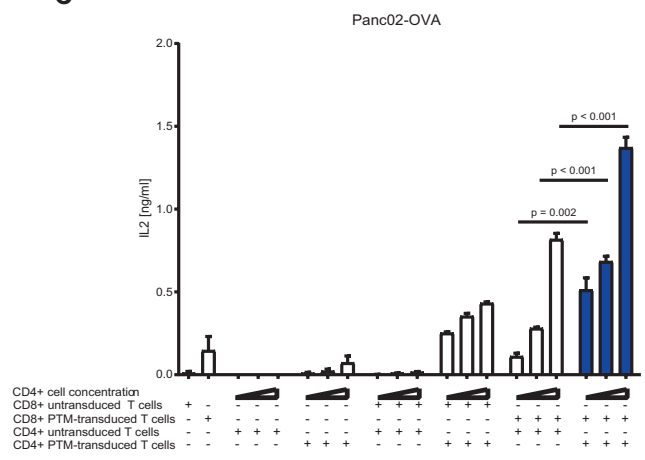

B

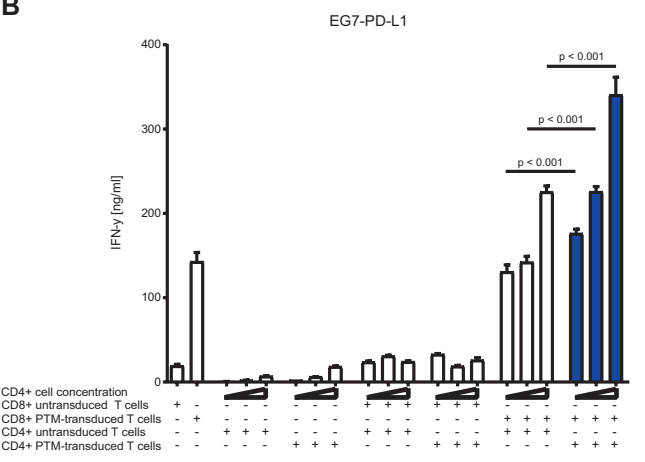

D

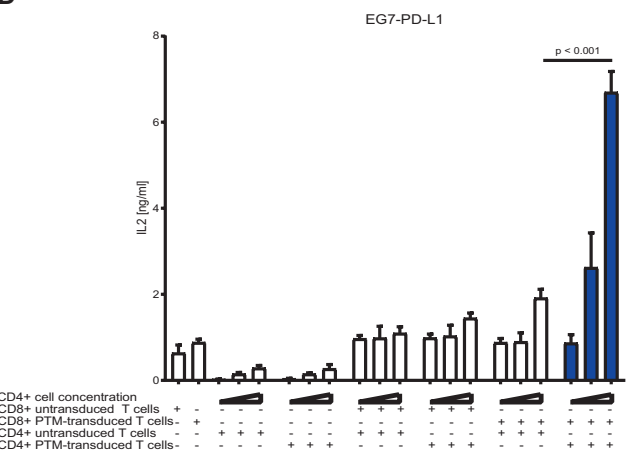

E

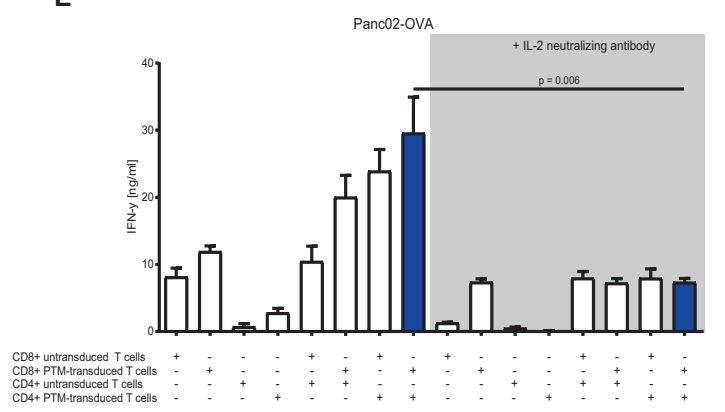

FIGURE 3 | In vitro characterization of PD1-CD28 fusion protein (PTM)-transduced CD4+ and CD8+ T cells in T cell-tumor cell cocultures at different CD4+ to CD8+ T cell ratios in the presence or absence of a neutralizing anti-IL-2-antibody. (A,B) PTM-transduced or untransduced primary murine OT-1, PTM-transduced or untransduced primary murine OT-2 T cells or combinations of these were prestimulated for $24 \mathrm{~h}$ with anti-CD3 antibodies plus recombinant PD-L1. Three different ratios of CD4+ to CD8+ T cells were applied (i.e., 3:1, 1:1, or 1:3 CD4+ to CD8+ T cell ratio). After prestimulation, the T cells were cocultured with Panc02-OVA or E.G7-PD-L1 cells for a further $48 \mathrm{~h}$. The resulting Interferon- $\gamma$ (IFN- $\gamma$ ) release was measured by enzyme linked immunosorbent assay (ELISA). (C,D) The concentration of interleukin-2 (IL-2) in the supernatants was measured by ELISA. (E) PTM-transduced or untransduced primary murine OT-1, PTM-transduced or untransduced primary murine OT-2 T cells or combinations of these were prestimulated for $24 \mathrm{~h}$ with anti-CD3 antibodies plus recombinant PD-L1. T cells were then cocultured with Panc02-OVA. In the blocking condition, a neutralizing anti-IL-2 antibody was present during the period of prestimulation and coculture. The resulting IFN- $\gamma$ release was measured by ELISA. Experiments (A-E) are representative of three independent experiments each performed at least in triplicates. Bars represent SEM and $P$ values from Student's t-test are shown. All tests are two-sided.

that rendered antigen-specific $\mathrm{CD} 8+\mathrm{T}$ cells resistant to $\mathrm{PD}$ 1-PD-L1-mediated anergy. Thus, we wondered if this would also apply to CD4+ T cells in a similar fashion (32). In the present manuscript, we could indeed transfer the activity of PTM to CD4+ T cells boosting $\mathrm{T}$ cell proliferation and cytokine production in the presence of cancer cells, which further underlines underpinning previous data using a CTLA-4-CD28 fusion receptor.
CD4+ $\mathrm{T}$ cells exert potent anti-tumoral effects on their own right $(10,15)$. This can be mediated either through direct recognition of MHC II+ tumor cells or indirectly through secretion of IFN- $\gamma$ and activation of bystander myeloid cells (15). In addition, $\mathrm{CD} 4+\mathrm{T}$ cells can support and contribute to $\mathrm{CD} 8+\mathrm{T}$ cell function (39-42). If transferred adoptively, $\mathrm{CD} 4+\mathrm{T}$ cells can even rescue anergic tumor infiltrating CD8+ $\mathrm{T}$ cells by $\mathrm{T}$ cell help (43). As our fusion protein essentially 


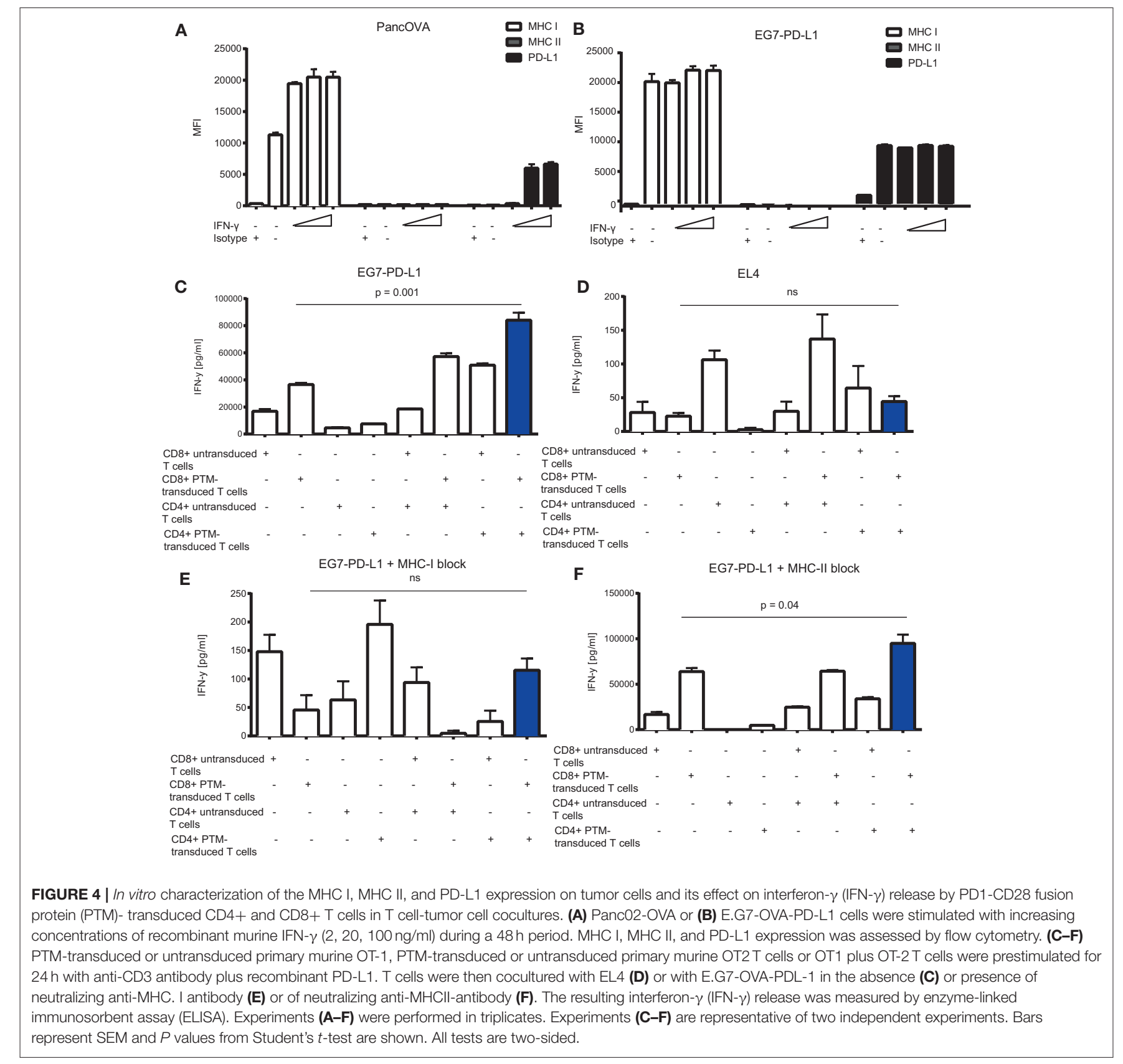

seems to further boost the function of the cell subsets either alone or in combination, we indeed observed that also the collaboration between CD4+ and CD8 $+\mathrm{T}$ cells was enhanced through introduction of PTM in both cell types. Interestingly, this effect was dependent on an optimal CD4+ to CD8+ T cell ratio, which is also in line with clinical observations observed with CAR T cells $(7,8)$. This is further confirmed in multiple studies dealing with mixtures of $\mathrm{CD} 4+$ and $\mathrm{CD} 8+\mathrm{T}$ cells for ACT (16-18). Notwithstanding the role of PD-1-mediated anergy, we argue and show that this brake is released by our PD1-CD28 fusion protein. Similar observations were reported with CTLA-4-CD28-expressing CD4+ and CD8+ T cells (38). Mechanistically, IL-2 derived from CD4+ $\mathrm{T}$ cells seems to mediate the synergistic effect of PD1-CD28 fusion receptortransduced CD4+ and CD8+ T cells. As IL-2 improves CD8+ $\mathrm{T}$ cell activation, proliferation, and persistence one could assume that the additional transfer of $\mathrm{CD} 4+\mathrm{T}$ cells would allow a lower dose of CD8 $+\mathrm{T}$ cells per patient. This would come with the additional advantage, that systemic IL-2 administration which often accompanies ACT protocols and causes significant side effects, could be prevented $(44,45)$. CD4+ $\mathrm{T}$ cells are also important for long-term protective anti-tumoral immunity 
$(46,47)$. In our hands, transduced CD4+ and CD8+ T cells predominantly developed a central memory phenotype. At least for CD8 $+\mathrm{T}$ cells longer persistence of CD8+ clones isolated from central memory $\mathrm{T}$ cells as compared to clones from CD8+ effector cells was observed in vivo after $\mathrm{T}$ cell transfer. This further indicates the importance of specific $\mathrm{T}$ cell subset functions for effective adoptive immunotherapy (48). An open question remains how CD4+-T cells would sense their antigen in vitro. We could demonstrate that OVA expression by the tumor cells, MHC I presentation and recognition of MHC I presented peptide by cocultured $\mathrm{CD} 8+\mathrm{T}$ cells was mandatory for $\mathrm{CD} 4+\mathrm{T}$ cell action. CD4+ T cells in general and OT-2 T cells in particular can be stimulated MHC II independently in the presence of large amounts of soluble antigen (49). OVA is known to be secreted by cells stably transfected with it and additional antigen release by CD8+-OT-1-T cells might lead to the level of antigen required for $\mathrm{CD} 4+\mathrm{T}$ cells in vitro. The exact role of this known mechanism in vivo is currently unclear but has been repeatedly shown in several models (15). In any case, the in vivo activity observed strongly suggests translational potential for this strategy. An open question is how much data from the OT-1OT-2 system will be transferrable to endogeneous antigens and to TCRs with different affinities. This antigen system is one of the most widely tested systems in $\mathrm{T}$ cell research. A significant amount of our knowledge has been generated in these models. Several studies suggest that data gathered from such preclinical studies will actually translate to clinical studies, corroborating the value of the OT-1-OT-2 system for translational $\mathrm{T}$ cell research $(50,51)$.

Antibodies, such as nivolumab, targeting the PD-1-PD-L1 axis can revive exhausted CD8 $+\mathrm{T}$ cells and have demonstrated impressive clinical activity $(52,53)$. However, more than $50 \%$ of PD-L1-positive tumors do not respond to anti-PD-L1/PD1 antibody treatment (54). In addition, treatment protocols using those antibodies often require multiple injections and cause significant toxicities to the patient (55). Based on our previous data we assume that a single dose of PD1$\mathrm{CD} 28$ fusion receptor-transduced $\mathrm{CD} 4+$ and $\mathrm{CD} 8+\mathrm{T}$ cells would induce tumor regression in vivo, significantly lowering potential side effects due to systemic $\mathrm{T}$ cell activation (32). Even PD-L1 negative tumors could be targeted by our combinatorial approach. Transduced CD4 $+\mathrm{T}$ cells can also be activated by interaction with PD-L2, another ligand of PD-1, expressed on antigen-presenting cells present in the tumor microenvironment.

In summary, our results indicate that PD1-CD28 fusion protein transduced CD4 $+\mathrm{T}$ cells have the potential to overcome the PD-1-PD-L1 immunosuppressive axis in pancreatic cancer and non-Hodgkin-lymphoma. Collectively, inhibiting PD-1 signaling in both CD4+ and CD8 $+\mathrm{T}$ cells might be the most effective way to enhance antitumor immunity. This data will need to be further investigated in other models while moving the approach toward translation.

\section{AUTHOR CONTRIBUTIONS}

FR designed experiments, supervised experiments, discussed data, and wrote the manuscript. FK designed experiments, conducted experiments, analyzed data, and wrote the manuscript. MC, SG, CH, and BC conducted experiments. PD and SE wrote the manuscript; SK designed and conceptualized the research, supervised the experiments, discussed data, and wrote the manuscript.

\section{FUNDING}

This work was supported by the Friedrich-Baur-Stiftung (to FR), Förderprogramm für Forschung und Lehre (to FR, SE and SK), FK received a stipend from the German Cancer Aid. Our studies are supported by grants from the Deutsche Forschungsgemeinschaft DFG DU 1522 1-1 (to PD), the international doctoral program i-Target: Immunotargeting of cancer funded by the Elite Network of Bavaria (to SK and SE), the Melanoma Research Alliance (grant number 409510 to SK), the Marie-Sklodowska-Curie Training Network for the Immunotherapy of Cancer (IMMUTRAIN, grant number 641549) funded by the H2020 program of the European Union (to SE and SK), the Else Kröner-Fresenius-Stiftung (to SK), the German Cancer Aid (to SK), the Ernst-Jung-Stiftung (to SK), the LMU Munich's Institutional Strategy LMUexcellent within the framework of the German Excellence Initiative (to SE and SK), the Bundesministerium für Bildung und Forschung VIP+ grant ONKATTRACT (to SE and SK) and the European Research Council Starting Grant (grant number 756017 to SK).

\section{SUPPLEMENTARY MATERIAL}

The Supplementary Material for this article can be found online at: https://www.frontiersin.org/articles/10.3389/fimmu. 2018.01955/full\#supplementary-material

Supplementary Figure 1 | Differentiation of PD1-CD28 fusion protein (PTM)-transduced CD4+ and CD8+ T cells in T cell-tumor cell cocultures. (A-D) PTM-transduced, untransduced primary murine OT-1, PTM-transduced, untransduced primary murine OT-2 T cells or OT-1 together with OT-2T cells were prestimulated for $24 \mathrm{~h}$ with anti-CD3 antibody and recombinant PD-L1. T cells were then cocultured with Panc02-OVA-PD-L1. CCR7 and CD62L expression on T cells was analyzed prior to and after $36 \mathrm{~h}$ of coculture by flow cytometry. Experiments (A-D) are representative of three independent experiments each performed at least in duplicates. Bars represent SEM.

Supplementary Figure 2 | Cytotoxic activity of PD1-CD28 fusion protein (PTM)-transduced CD4+ and CD8+ T cells in T cell-tumor cell coculture in the presence of an Interleukin-2 (IL-2) neutralizing antibody. PTM-transduced, untransduced primary murine OT-1, PTM-transduced, untransduced primary murine OT-2 T cells or OT-1 together with OT-2 T cells were prestimulated for $24 \mathrm{~h}$ with anti-CD3 antibody and recombinant PD-L1. T cells were then cocultured with Panc02-OVA in the presence or absence of neutralizing anti-IL-2 antibody and $\mathrm{LDH}$ release from lysed tumor cells was measured. The experiment was performed in quadruplicates. Bars represent SEM and $P$ values from Student's $t$-test are shown. All tests are two-sided. 


\section{REFERENCES}

1. Ioannides CG, Whiteside TL. T cell recognition of human tumors: implications for molecular immunotherapy of cancer. Clin Immunol Immunopathol. (1993) 66:91-106. doi: 10.1006/clin.1993.1012

2. Kobold S, Duewell P, Schnurr M, Subklewe M, Rothenfusser S, Endres S. Immunotherapy in Tumors. Dtsch Arztebl Int. (2015) 112:809-15. doi: 10.3238/arztebl.2015.0809

3. Rosenberg SA, Restifo NP. Adoptive cell transfer as personalized immunotherapy for human cancer. Science (2015) 348:62-8. doi: $10.1126 /$ science.aaa4967

4. Geukes Foppen MH, Donia M, Svane IM, Haanen JB. Tumor-infiltrating lymphocytes for the treatment of metastatic cancer. Mol Oncol. (2015) 9:191835. doi: 10.1016/j.molonc.2015.10.018

5. Liu Y, Chen X, Han W, Zhang Y. Tisagenlecleucel, an approved anti-CD19 chimeric antigen receptor T-cell therapy for the treatment of leukemia. Drugs Today (2017) 53:597-608. doi: 10.1358/dot.2017.53.11.2725754

6. Riddell SR, Sommermeyer D, Berger C, Liu LS, Balakrishnan A, Salter A, et al. Adoptive therapy with chimeric antigen receptor-modified $\mathrm{T}$ cells of defined subset composition. Cancer J. (2014) 20:141-4. doi: 10.1097/PPO.0000000000000036

7. Turtle CJ, Hanafi LA, Berger C, Gooley TA, Cherian S, Hudecek M, et al. CD19 CAR-T cells of defined CD4+:CD8+ composition in adult B cell ALL patients. J Clin Invest. (2016) 126:2123-38. doi: 10.1172/JCI85309

8. Turtle CJ, Hanafi LA, Berger C, Hudecek M, Pender B, Robinson E, et al. Immunotherapy of non-Hodgkin's lymphoma with a defined ratio of CD8+ and CD4+ CD19-specific chimeric antigen receptor-modified T cells. Sci Transl Med. (2016) 8:355ra116. doi: 10.1126/scitranslmed.aaf8621

9. Gardner RA, Finney O, Annesley C, Brakke H, Summers C, Leger K, et al. Intent-to-treat leukemia remission by CD19 CAR T cells of defined formulation and dose in children and young adults. Blood (2017) 129:3322-31. doi: 10.1182/blood-2017-02-769208

10. Tran E, Turcotte S, Gros A, Robbins PF, Lu YC, Dudley ME, et al. Cancer immunotherapy based on mutation-specific CD4+ T cells in a patient with epithelial cancer. Science (2014) 344:641-5. doi: 10.1126/science.1251102

11. Voigt C, May P, Gottschlich A, Markota A, Wenk D, Gerlach I, et al. Cancer cells induce interleukin-22 production from memory CD4(+) T cells via interleukin-1 to promote tumor growth. Proc Natl Acad Sci USA. (2017) 114:12994-9. doi: 10.1073/pnas.1705165114

12. Baxevanis CN, Voutsas IF, Tsitsilonis OE, Gritzapis AD, Sotiriadou R, Papamichail M. Tumor-specific CD4+ T lymphocytes from cancer patients are required for optimal induction of cytotoxic $\mathrm{T}$ cells against the autologous tumor. J Immunol. (2000) 164:3902-12. doi: 10.4049/jimmunol.164.7.3902

13. Marzo AL, Kinnear BF, Lake RA, Frelinger JJ, Collins EJ, Robinson BW, et al. Tumor-specific CD4+ $\mathrm{T}$ cells have a major post-licensing role in CTL mediated anti-tumor immunity. J Immunol. (2000) 165:6047-55. doi: 10.4049/jimmunol.165.11.6047

14. Hunziker L, Klenerman P, Zinkernagel RM, Ehl S. Exhaustion of cytotoxic $\mathrm{T}$ cells during adoptive immunotherapy of virus carrier mice can be prevented by B cells or CD4+ T cells. Eur J Immunol. (2002) 32:374-82. doi: 10.1002/1521-4141(200202)32:2<374::AID-IMMU374>3.0.CO;2-9

15. Haabeth OA, Tveita AA, Fauskanger M, Schjesvold F, Lorvik KB, Hofgaard $\mathrm{PO}$, et al. How do CD4(+) T cells detect and eliminate tumor cells that either lack or express MHC class II molecules? Front Immunol. (2014) 5:174. doi: 10.3389/fimmu.2014.00174

16. Moeller M, Haynes NM, Kershaw MH, Jackson JT, Teng MW, Street SE, et al. Adoptive transfer of gene-engineered CD4+ helper T cells induces potent primary and secondary tumor rejection. Blood (2005) 106:2995-3003. doi: 10.1182/blood-2004-12-4906

17. Kennedy R, Celis E. T helper lymphocytes rescue CTL from activation-induced cell death. J Immunol. (2006) 177:2862-72. doi: 10.4049/jimmunol.177.5.2862

18. Wang LX, Shu S, Disis ML, Plautz GE. Adoptive transfer of tumor-primed, in vitro-activated, CD4+ T effector cells, (TEs) combined with CD8 + TEs provides intratumoral TE proliferation and synergistic antitumor response. Blood (2007) 109:4865-76. doi: 10.1182/blood-2006-09-045245

19. Griffith KD, Read EJ, Carrasquillo JA, Carter CS, Yang JC, Fisher B, et al. In vivo distribution of adoptively transferred indium-111-labeled tumor infiltrating lymphocytes and peripheral blood lymphocytes in patients with metastatic melanoma. J Natl Cancer Inst. (1989) 81:1709-17. doi: 10.1093/jnci/81.22.1709

20. Bourquin C, von der Borch P, Zoglmeier C, Anz D, Sandholzer N, Suhartha N, et al. Efficient eradication of subcutaneous but not of autochthonous gastric tumors by adoptive $\mathrm{T}$ cell transfer in an SV40 T antigen mouse model. $J$ Immunol. (2010) 185:2580-8. doi: 10.4049/jimmunol.0903231

21. Riella LV, Paterson AM, Sharpe AH, Chandraker A. Role of the PD-1 pathway in the immune response. Am J Transplant (2012) 12:2575-87. doi: 10.1111/j.1600-6143.2012.04224.x

22. Arasanz H, Gato-Canas M, Zuazo M, Ibanez-Vea M, Breckpot K, Kochan $\mathrm{G}$, et al. PD1 signal transduction pathways in T cells. Oncotarget (2017) 8:51936-45. doi: 10.18632/oncotarget.17232

23. Gibbons Johnson RM, Dong H. Functional expression of programmed deathligand 1, (B7-H1) by immune cells and tumor cells. Front Immunol. (2017) 8:961. doi: 10.3389/fimmu.2017.00961

24. Dong H, Strome SE, Salomao DR, Tamura H, Hirano F, Flies DB, et al. Tumor-associated B7-H1 promotes T-cell apoptosis: a potential mechanism of immune evasion. Nat Med. (2002) 8:793-800. doi: 10.1038/nm730

25. Wang X, Teng F, Kong L, Yu J. PD-L1 expression in human cancers and its association with clinical outcomes. Onco Targets Ther. (2016) 9:5023-39. doi: 10.2147/OTT.S105862

26. Abate-Daga D, Hanada K, Davis J, LYang JC, Rosenberg SA, Morgan RA. Expression profiling of TCR-engineered T cells demonstrates overexpression of multiple inhibitory receptors in persisting lymphocytes. Blood (2013) 122:1399-410. doi: 10.1182/blood-2013-04-495531

27. Daud AI, Wolchok JD, Robert C, Hwu WJ, Weber JS, Ribas A, et al. Programmed death-ligand 1 expression and response to the anti-programmed death 1 antibody pembrolizumab in melanoma. J Clin Oncol. (2016) 34:41029. doi: 10.1200/JCO.2016.67.2477

28. Alsaab HO, Sau S, Alzhrani R, Tatiparti K, Bhise K, Kashaw SK, et al. PD1 and PD-L1 checkpoint signaling inhibition for cancer immunotherapy: mechanism, combinations, and clinical outcome. Front Pharmacol. (2017) 8:561. doi: 10.3389/fphar.2017.00561

29. Iafolla MAJ, Juergens RA. Update on programmed death-1 and programmed death-ligand 1 inhibition in the treatment of advanced or metastatic nonsmall cell lung cancer. Front Oncol. (2017) 7:67. doi: 10.3389/fonc.2017. 00067

30. Malhotra J, Jabbour SK, Aisner J. Current state of immunotherapy for non-small cell lung cancer. Transl Lung Cancer Res. (2017) 6:196-211. doi: $10.21037 /$ tlcr.2017.03.01

31. Abdin SM, Zaher DM, Arafa EA, Omar HA. Tackling cancer resistance by immunotherapy: updated clinical impact and safety of PD1/PD-L1 inhibitors. Cancers (2018) 10:32. doi: 10.3390/cancers100 20032

32. Kobold S, Grassmann S, Chaloupka M, Lampert C, Wenk S, Kraus F, et al. Impact of a new fusion receptor on $\mathrm{PD}$-1-mediated immunosuppression in adoptive $\mathrm{T}$ cell therapy. J Natl Cancer Inst. (2015) 107:146. doi: 10.1093/jnci/djv146

33. Duewell P, Kisser U, Heckelsmiller K, Hoves S, Stoitzner P, Koernig S, et al. ISCOMATRIX adjuvant combines immune activation with antigen delivery to dendritic cells in vivo leading to effective cross-priming of CD8+ T cells. J Immunol. (2011) 187:55-63. doi: 10.4049/jimmunol.10 04114

34. Leisegang M, Engels B, Meyerhuber P, Kieback E, Sommermeyer D, Xue SA, et al. Enhanced functionality of $\mathrm{T}$ cell receptor-redirected $\mathrm{T}$ cells is defined by the transgene cassette. J Mol Med. (2008) 86:573-83. doi: 10.1007/s00109-008-0317-3

35. Mueller K, von Massenhausen A, Aichele U, Starck L, Leisegang M, Uckert W, et al. Protective capacity of virus-specific $\mathrm{T}$ cell receptortransduced CD8 T cells in vivo. J Virol. (2012) 86:10866-9. doi: 10.1128/JVI.01 472-12

36. Kobold S, Steffen J, Chaloupka M, Grassmann S, Henkel J, Castoldi $\mathrm{R}$, et al. Selective bispecific $\mathrm{T}$ cell recruiting antibody and antitumor activity of adoptive T cell transfer. J Natl Cancer Inst. (2015) 107:364. doi: $10.1093 /$ jnci/dju364

37. Rapp M, Grassmann S, Chaloupka M, Layritz P, Kruger S, Ormanns S, et al. C-C chemokine receptor type- 4 transduction of $\mathrm{T}$ cells enhances 
interaction with dendritic cells, tumor infiltration and therapeutic efficacy of adoptive T cell transfer. Oncoimmunology (2016) 5:e1105428. doi: 10.1080/2162402X.2015.1105428

38. Shin JH, Park HB, Oh YM, Lim DP, Lee JE, Seo HH, et al. Positive conversion of negative signaling of CTLA4 potentiates antitumor efficacy of adoptive T-cell therapy in murine tumor models. Blood (2012) 119:5678-87. doi: 10.1182/blood-2011-09-380519

39. Keene JA, Forman J. Helper activity is required for the in vivo generation of cytotoxic T lymphocytes. J Exp Med. (1982) 155:768-82. doi: 10.1084/jem.155.3.768

40. Matloubian M, Concepcion RJ, Ahmed R. CD4+ T cells are required to sustain CD8+ cytotoxic T-cell responses during chronic viral infection. J Virol. (1994) 68:8056-63.

41. Bos R, Sherman LA. CD4+ T-cell help in the tumor milieu is required for recruitment and cytolytic function of CD8+ T lymphocytes. Cancer Res. (2010) 70:8368-77. doi: 10.1158/0008-5472.CAN-10-1322

42. Schietinger A, Philip M, Liu RB, Schreiber K, Schreiber H. Bystander killing of cancer requires the cooperation of $\mathrm{CD}^{+}$and $\mathrm{CD} 8^{+} \mathrm{T}$ cells during the effector phase. J Exp Med. (2010) 207:2469-77. doi: 10.1084/jem.20092450

43. Arina A, Karrison T, Galka E, Schreiber K, Weichselbaum RR, Schreiber H. Transfer of allogeneic CD4+ T cells rescues CD8 $+\mathrm{T}$ cells in anti-PD-L1resistant tumors leading to tumor eradication. Cancer Immunol Res. (2017) 5:127-36. doi: 10.1158/2326-6066.CIR-16-0293

44. Bindon C, Czerniecki M, Ruell P, Edwards A, McCarthy WH, Harris R, et al. Clearance rates and systemic effects of intravenously administered interleukin 2, (IL-2) containing preparations in human subjects. Br J Cancer (1983) 47:123-33. doi: 10.1038/bjc.1983.15

45. Rosenberg SA, Yannelli JR, Yang JC, Topalian SL, Schwartzentruber DJ, Weber JS, et al. Treatment of patients with metastatic melanoma with autologous tumor-infiltrating lymphocytes and interleukin 2. J Natl Cancer Inst. (1994) 86:1159-66. doi: 10.1093/jnci/86.15.1159

46. Hu HM, Winter H, Urba WJ, Fox BA. Divergent roles for CD4+ T cells in the priming and effector/memory phases of adoptive immunotherapy. J Immunol. (2000) 165:4246-53. doi: 10.4049/jimmunol.165.8.4246

47. Shedlock DJ, Shen H. Requirement for CD4 T cell help in generating functional CD8 T cell memory. Science (2003) 300:337-9. doi: $10.1126 /$ science. 1082305

48. Golubovskaya $\mathrm{V}, \mathrm{Wu}$ L. Different subsets of $\mathrm{T}$ cells, memory, effector functions, and CAR-T immunotherapy. Cancers (2016) 8:36. doi: $10.3390 /$ cancers 8030036
49. Li M, Davey GM, Sutherland RM, Kurts C, Lew AM, Hirst C, et al. Cell-associated ovalbumin is cross-presented much more efficiently than soluble ovalbumin in vivo. J Immunol (2001) 166:6099-103. doi: 10.4049/jimmunol.166.10.6099

50. Graef P, Buchholz VR, Stemberger C, Flossdorf M, Henkel L, Schiemann $M$, et al. Serial transfer of single-cell-derived immunocompetence reveals stemness of $\mathrm{CD}^{+}$central memory T cells. Immunity (2014) 41:116-26. doi: 10.1016/j.immuni.2014.05.018

51. Neuenhahn M, Albrecht J, Odendahl M, Schlott F, Dossinger G, Schiemann $\mathrm{M}$, et al. Transfer of minimally manipulated CMV-specific T cells from stem cell or third-party donors to treat CMV infection after allo-HSCT. Leukemia (2017) 31:2161-71. doi: 10.1038/leu.2017.16

52. Robert C, Long GV, Brady B, Dutriaux C, Maio M, Mortier L, et al. Nivolumab in previously untreated melanoma without BRAF mutation. $N$ Engl J Med. (2015) 372:320-30. doi: 10.1056/NEJMoa1412082

53. Zheng P, Zhou Z. Human cancer immunotherapy with PD-1/PD-L1 blockade. Biomark Cancer (2015) 7(Suppl 2):15-8. doi: 10.4137/BIC. S29325

54. Topalian SL, Hodi FS, Brahmer JR, Gettinger SN, Smith DC, McDermott DF, et al. Safety, activity, and immune correlates of anti-PD-1 antibody in cancer. $N$ Engl J Med. (2012) 366:2443-54. doi: 10.1056/NEJMoa12 00690

55. Postow MA, Chesney J, Pavlick AC, Robert C, Grossmann K, McDermott D, et al. Nivolumab and ipilimumab versus ipilimumab in untreated melanoma. N Engl J Med. (2015) 372:2006-17. doi: 10.1056/NEJMoa1414428

Conflict of Interest Statement: Data of this work have been generated for the doctoral thesis of FK and BC at the Ludwig-Maximilians-Universität München.

The remaining authors declare that the research was conducted in the absence of any commercial or financial relationships that could be construed as a potential conflict of interest.

Copyright (C) 2018 Rataj, Kraus, Chaloupka, Grassmann, Heise, Cadilha, Duewell, Endres and Kobold. This is an open-access article distributed under the terms of the Creative Commons Attribution License (CC BY). The use, distribution or reproduction in other forums is permitted, provided the original author(s) and the copyright owner(s) are credited and that the original publication in this journal is cited, in accordance with accepted academic practice. No use, distribution or reproduction is permitted which does not comply with these terms. 